\title{
Drop Out and "Disconnected" Young Adults: Examining the Impact of Neighborhood and School Contexts
}

\author{
Maria G. Rendón
}

Published online: 28 June 2013

(C) The Author(s) 2013. This article is published with open access at Springerlink.com

\begin{abstract}
Using data from the National Longitudinal Study of Adolescent Health (Add Health) this study compares if and how neighborhood effects on the likelihood to drop out and be "disconnected" from school and work in young adulthood change when schools are taken into account. As widely documented, I find that neighborhood socioeconomic status is associated with dropping out, but this effect is mediated by schools with high numbers of Latino or Black students. I find neighborhood socioeconomic status is not associated with being disconnected, yet, attending schools with high numbers of Black students is. This research draws attention for the need to account for neighborhood and school effects simultaneously to better understand contextual effects and to more carefully conceptualize how neighborhood and schools work together to produce these outcomes disproportionately impacting racial and ethnic minorities.
\end{abstract}

Keywords Neighborhood effects - School effects - High school dropout . Disconnected youth $\cdot$ Racial/ethnic disparities

The transition to adulthood literature has drawn attention to the importance of examining social disparities in the young adult years (Settersten et al. 2005; Osgood et al. 2006). Research shows that among the most vulnerable to making an unsuccessful transition to adulthood-those most likely to make up America's poor in their adult life—are individuals who lack a high school degree and those detached

\footnotetext{
M. G. Rendón ( $ه)$

Department of Planning, Policy and Design, University of California, Irvine, 202 Social Ecology I, Irvine, CA 92697-7075, USA

e-mail: mgrendon@uci.edu

M. G. Rendón

Sociology and Social Policy, Harvard University, Cambridge, MA, USA
} 
from school and the labor market in their early adult years, the "disconnected." Numerous studies show that high school non-completers and those disconnected for several years have lower earnings over their adult years, higher unemployment rates, they experience a harder time securing a job and are more likely to rely on public assistance relative to those who obtain a high school degree or are connected to school or work (Besharov 1999; Brown and Emig 1999; Hair et al. 2009; Rumberger 2011).

This study examines whether an unsuccessful transition into adulthood can be explained, in part, by the neighborhood and/or school contexts young adults were exposed to in their adolescence. Numerous studies find individual-level factors are associated with high school non-completion and being disconnected. Yet social scientists have long considered the social contexts in which individuals develop to influence life outcomes. In particular, strong theoretical claims have been made that neighborhood conditions influence socioeconomic trajectories above and beyond individual factors (Massey and Denton 1993; Wilson 1987, 1996). It is argued that growing up in disadvantaged contexts truncate educational attainment and work prospects. Yet, exactly why growing up in contexts would lead to such poor outcomes continues to be examined. While theoretical work exists on how neighborhoods might shape socioeconomic trajectories, it remains unclear if neighborhoods contribute to these outcomes directly or indirectly and how. Despite voluminous empirical studies on neighborhoods effects, few examine the mechanisms or social processes that drive neighborhood effects (Harding et al. 2011; Sampson et al. 2002). This is a serious limitation in the literature given scholars have called upon researchers to more seriously consider how neighborhoods impact the schooling process. For instance, Noguera (2003) argues more education researchers need to examine the "urban" in urban schooling. Doing so remains important given ongoing skepticism that neighborhoods matter and studies suggesting only individual factors (Plotnick and Hoffman 1999) or school context characteristics shape education or work-related outcomes (Dobbie and Fryer 2009).

In this study, I pay special attention to the relationship that exists between neighborhoods and schools in shaping these outcomes. There are various ways to conceptualize the relationship between neighborhoods and schools. In his review of the literature, Johnson (2012) describes seven models that exist of neighborhoodinstitutional relationships focused on educational outcomes. $\mathrm{He}$ finds most neighborhood-effect studies take on an "endogenous institution model," whereby individual, family and neighborhood qualities are examined as exogenous factors, while schools are omitted. As a result, very few empirical studies examine neighborhoods and schools simultaneously (but see Ainsworth 2002; Briggs et al. 2008; Cook et al. 2002; Cook 2003; Goldsmith 2009; Owens 2010; Pong and Hao 2007; Sanbonmatsu et al. 2006; Sykes and Musterd 2011). In part, this omission reflects dataset limitations. Yet, as Johnson (2012) explains, the omission of institutions suggests that "the effects of schools may be no different in quality than those of neighborhoods (p. 484)." Of course, this underlying premise is highly contested among those who consider schools to have an independent impact on educational outcomes (Johnson 2010) or those who examine schools as part of an organizational structure that matters as well (Arum 2000). While empirical studies 
offer minimal consensus in how neighborhoods and schools should be modeled, the literature has theoretically identified schools as important neighborhood institutions that ought to be accounted for, especially in studies focused on education and workrelated outcomes (Ellen and Turner 1997; Jencks and Mayer 1990; Leventhal and Brooks-Gunn 2000; Sampson et al. 2002).

Therefore, this study aims to make a contribution to this contested body of work by simultaneously accounting for neighborhood and school contextual factors. I examine whether neighborhood or school factors, or both, influence the likelihood to dropout or be disconnected as young adults. Given schools remain primary neighborhood institutions, I examine if school contexts mediate neighborhood effects on these outcomes. Specifically, I examine if school effects mediate the effect of neighborhood socioeconomic status (SES). Neighborhood SES is one of the most consistent neighborhood effects found across multiple studies. However, it remains unclear how neighborhood affluence or disadvantage functions to impact life outcomes, including education and work-related attainment. It could be that direct exposure to affluent or poor neighbors shapes life outcome through the transmission of information or cultural orientations. Alternatively, neighborhood SES effects could work through its institutions, like schools, which can be resource rich or depleted.

Further, this study draws special attention to the outcomes of Blacks and Latinos. The dropout rate for Blacks and Latinos is at least two times higher than for whites (Fry 2003; Rumberger 2011) and studies show these groups are overrepresented among the "disconnected" (Brown and Emig 1999; Landale et al. 1998; Oropesa and Landale 2009; Powers 1994). Most neighborhood effects research has focused on the experience of Blacks in urban neighborhoods (Massey and Denton 1993; Wilson 1987, 1996). Yet, demographics have changed rapidly since these seminal studies and scholars studying the integration process of immigrants and their children suggest that the concentration of these groups in urban neighborhoods is also detrimental. For instance, some scholars suggest Mexican Americans, who hold the highest dropout rate in the U.S., is a group at risk of "downward assimilation" into an "underclass" (Portes and Zhou 1993; Haller et al. 2011). Therefore, this study examines racial/ethnic disparities in the odds to dropout and be disconnected, taking into account Latino national origin and generational status.

While this analysis is limited in its ability to identify clear neighborhood or school mechanisms that may contribute to dropping out or being disconnected, the study does suggest whether these social processes are more likely to take place at the neighborhood or school level, and possible interactions among the two. Disentangling neighborhood from school effects is ultimately critical for policy or intervention considerations if a goal is to reduce the number of high school dropouts and those who are disconnected in the young adult years in the most efficient or promising way. It is particularly important to understand if interventions should be aimed at schools or neighborhoods to address persistent racial/ethnic disparities. 


\section{Neighborhood Effects}

While researchers continue to examine issues of selection (Sampson and Sharkey 2008; Sharkey 2012; Sharkey and Elwert 2011), many studies find neighborhoods have an independent impact on life outcomes above and beyond individual characteristics (Brooks-Gunn et al. 1993; Burdick-Will et al. 2011; Leventhal and Brooks-Gunn 2000; Sampson et al. 2002). Some scholars have made strong arguments that racial segregation across neighborhoods shapes life outcomes (Massey and Denton 1993). Yet, in reviewing the literature, I find few empirical studies support this claim, specifically the argument that segregation by race is detrimental (Burdick-Will et al. 2011; Johnson 2010). Researchers have also examined if immigrant and/or Latino concentration matters, but these studies also find mixed results. Some studies find that immigrant concentration attenuates the negative effects of poverty concentration and is associated with positive outcomes, such as better health (Aneshensel and Sucoff 1996; Bond-Huie et al. 2002; Cubbin et al. 2005; Moore and Pinderhughes 1993; Upchurch et al. 1999) and lower rates of violence (Krueger et al. 2004; Sampson et al. 2005). However, Pong and Hao (2007) find immigrant concentration is associated with lower academic achievement, while Frank et al. (2007) find Latino concentration in Los Angeles associated with greater substance use and delinquency. These studies suggest racial or ethnic segregation matters differently depending on the outcome in question.

Instead, the literature shows that the most consistent and strongest neighborhood characteristic associated with life outcomes is neighborhood socioeconomic status (SES), a contextual factor highly correlated with, yet distinct from, racial and ethnic segregation (Burdick-Will et al. 2011; Johnson 2010; Leventhal and Brooks-Gunn 2000). For instance, neighborhoods of low socioeconomic composition are associated with infant mortality, low birth weight, teenage pregnancy and adolescent delinquency and homicide (Brooks-Gunn et al. 1997; Kawachi and Berkman 2003; Sampson et al. 2002). Among these studies are those that find that neighborhood disadvantage is associated with educational outcomes, including lower school achievement (Ainsworth 2002; Card and Rothstein 2007; Pong and Hao 2007) and higher odds of dropping out (Clark 1992; Crane 1991; Ensminger et al. 1996; Harding 2003).

Despite voluminous studies on neighborhood effects, few examine the social processes at the neighborhood context that produce different outcomes. That is, exactly why neighborhood SES influences life outcomes remains understudied. For instance, while studies find neighborhood SES is associated with dropping out, there is still no clear conceptualization of how neighborhoods contribute to this problem specifically (Goldsmith 2009; Harding et al. 2011). For instance, Crane (1991) found that dropping out was contagious and spread through peer influence in the most disadvantaged neighborhoods that experience this "epidemic." Yet new research suggests that what contributes to high dropout rates in poor neighborhoods is related to the high levels of violence there (Burdick-Will et al. 2011; Harding 2010; also see Sharkey 2010). Therefore, to better understand the mechanisms that drive high dropout rates in poor neighborhoods-whether it is cultural transmission, social dynamics around issues of violence or other factors-more research is needed. 
One significant limitation in this literature-specifically as it relates to educational attainment and work-related outcomes-is the minimal attention schools receive as either competing with or mediating neighborhood effects (Arum 2000; Goldsmith 2009; Johnson 2012; Sykes and Musterd 2011). This is problematic given that most children and youth spend more time in schools than in neighborhoods per se, making it possible that schools trump neighborhoods in shaping life outcomes. For instance, youth may be exposed to role models or gain access to social capital and/or be exposed to negative peer ties specifically in school. School contexts may also influence these outcomes for other reasons, such as through curriculum or school quality measures. Moreover, schools exacerbate inequities across neighborhoods as better resourced parents often select into higher quality schools leaving behind the most disadvantaged students in traditional neighborhood public schools. For instance, it could be that social capital (Wilson 1987, 1996) or oppositional culture (Fordham and Ogbu 1986; Ogbu 1991; Portes and Zhou 1993) believed to contribute to poor outcomes in disadvantaged contexts is not transmitted via the neighborhood, but the school context instead. Alternatively, neighborhoods and school may interact in poorly understood ways. Another possibility is that what happens in schools may feedback into neighborhoods (see Mateu-Gelabert and Lune 2003) or these contextual effects may offset each other. In sum, as long as schools remain one of the most prominent institutions of neighborhoods, omitting them in neighborhood effect studies presents a serious limitation in this body of work.

\section{School Effects}

The neglect of schools in "neighborhood effect" studies may not be too surprising when one considers that social scientists have questioned the extent to which school contexts influence educational outcomes. In 1966, The Coleman report concluded family background characteristics were the strongest predictors of educational attainment and that school contexts did not play a strong role in shaping educational disparities between Blacks and Whites. Influential studies thereafter supported these claims (Jencks et al. 1972; Mosteller and Moynihan 1972). Since then, however, multilevel statistical modeling has allowed researchers to re-examine the original Coleman data and correct for methodological limitations at the time (Borman and Dowling 2010; Konstantopoulos and Borman 2011). These studies and many others using similar methods with more contemporary datasets find that, in fact, school contexts do contribute to educational outcomes above and beyond individual attributes (Lee 2000; Raudenbush and Willms 1995). Most of these studies focus on academic achievement as measured through various tests (Hanushek et al. 2009; Rumberger and Palardy 2005). Yet, some studies also find the school context factors influences educational attainment. For instance, Rumberger and Lim (2008) find that school contexts characteristics account for roughly $20 \%$ of the variability in high school non-completion. 
Concern over racial/ethnic segregation across schools has been at the center of many of these studies (Borman and Dowling 2010; Hanushek et al. 2009; Konstantopoulos and Borman 2011; Orfield and Eaton 1997; Rumberger and Palardy 2005). Several studies find that the concentration of racial and ethnic minority students in schools negatively contributes to educational outcomes, including high school non-completion (Guryan 2004; Hanushek et al. 2009; Hoxby 2000; McNeal 1997; Rumberger 1995; Sander 2001). Yet exactly why predominantly minority schools contribute to poor educational outcomes is theoretically underdeveloped. Some studies suggest attending a predominantly minority school contributes to poor educational outcomes because peers in these schools transmit lower aspirations, expectations or attitudes. This is consistent with the argument in the neighborhood effects literature that it is the transmission of normative cultural orientations in the urban context that drives poor outcomes (Fordham and Ogbu 1986; Ogbu 1991; Portes and Zhou 1993; Wilson 1987). Importantly, some studies find peer-effects are endogenous and for this reason they argue peer-effects are overstated (Evans et al. 1992; Rivkin 2001).

Other scholars argue that it is not so much the racial/ethnic composition of students that produces negative outcomes directly, but instead underlying unequal distribution of resources associated with the racial/ethnic composition of schools (Orfield and Eaton 1997; Bennett 2011). For example, several studies find that compositional characteristics of schools become insignificant once structural, resource and school practice variables are taken into account, including academic climate and teacher relations (Lee and Burkam 2003; Rumberger and Palardy 2005). As such, several studies find that it is the socioeconomic composition of schools, rather than the racial/ethnic demographics, which impacts high school noncompletion (Rumberger and Thomas 2000). One interpretation is that the concentration of higher socioeconomic students translates to greater social capital in affluent schools (Noguera 2003). More generally, various aspects of schools and schooling are believed to contribute to educational outcomes above and beyond individual and family background characteristics. This body of work includes studies that examine how the structure of schools (size, public/private, etc.), school resources (qualified teachers, expenditure per pupil, etc.) and schooling practices (teaching practices, climate, teacher-student relationships, policies like expulsion, compulsory schooling age, etc.) impact educational outcomes.

While expansive, this body of work is not without limitations. Many of these studies assume neighborhood conditions are important in shaping inequities across schools (Noguera 2003), but few attempt to isolate neighborhood from school effects. For instance, it is widely taken for granted that school conditions or school practices are influenced or shaped by neighborhood characteristics, but few studies examine how this occurs. One of the few studies to do so by Mateu-Gelabert and Lune (2003) find substantial overlap in neighborhood and school youth conflicts, suggesting a lot of fluidity between social processes in neighborhoods and schools. This study suggests school's social climate and perhaps school-policies are intimately related to characteristics of the neighborhood. Neighborhood and school processes may be related in other ways. In their study, Card and Rothstein (2007) found significant neighborhood effects on SAT scores, but no significant direct 
school segregation effects on this outcome. By examining within-school factors they found white students were more likely to enroll in honors classes in cities with more integrated schools, suggesting that neighborhood integration negatively impacted racial/ethnic minority students through school tracking. Therefore, how neighborhood conditions impact school processes, or vice versa, requires closer examination of how these two embedded contexts work together to produce various outcomes. This remains a grossly understudied area of research.

\section{This Study}

I examine if neighborhood and school contextual factors are associated with being a high school dropout and being "disconnected" (i.e. not working or going to school) in young adulthood. These two terms - dropout and disconnected—are occasionally used to refer to the same population. Yet someone who did not complete high school may very well be strongly attached to the labor market or be pursuing higher education. Alternatively, someone who graduated from high school may not be attached to the labor market or be pursuing higher education. Therefore, while these two outcomes may be related, they are distinct outcomes that should be examined separately. As such, this study adds to existing work that examines if and how neighborhood and school contexts impact educational attainment. Further, it adds to limited research that examines contextual effects on being disconnected. Currently, most research on the disconnected treat neighborhood characteristics in their models as individual traits and not contextual characteristics, i.e., they do not account for clustering of individuals within neighborhoods (Case and Katz 1991; Powers 1994; Landale et al. 1998). One exception is Cutler and Glaeser (1997) who did find that exposure to segregated contexts was harmful to Blacks, increasing not only their odds to dropout but also to be "idle" (i.e., disconnected). This study adds to this work.

Most importantly, this study examines neighborhood and school context factors simultaneously. Most studies examining if social contexts are associated with education and/or work-related outcomes focus on either neighborhood or school effects (McNeal 1997; Portes and MacLeod 1996; Portes and Hao 2004; Rumberger 1995; Raudenbush and Willms 1995). The few studies that examine both contexts find mixed results; some find only neighborhood effects (Card and Rothstein 2007; Garner and Raudenbush 1991), others only school effects (Teitler and Weiss 2000; Goldsmith 2009; Sykes and Musterd 2011) and some find evidence that both contexts are significantly associated with education outcomes (Ainsworth 2002; Bennett 2011; Catsambis and Andrew 2001; Owens 2010; Pong and Hao 2007). Therefore, this study aims to contribute to this research, paying special attention to whether school contexts mediate neighborhood effects and whether contextual facts help explain differences in these outcomes across racial/ethnic groups. Specifically, this study asks the following:

(1) Are neighborhood characteristics associated with higher odds of remaining a high school "dropout" or being "disconnected" in the young adult years? 
(2) Are school context characteristics associated with these outcomes and do they mediate neighborhood effects?

(3) Do neighborhood and school contexts help explain differences in these outcomes across racial/ethnic groups?

The data used in these analyzes allow me to examine various neighborhood and school compositional factors. Regrettably, I am unable to examine neighborhoodspecific social processes believed to be associated with these outcomes (i.e., social capital, cultural orientations, etc.). Yet I am able to compare if and how neighborhood effects change by taking the school context into accounting. Further, I am able to examine if a school's socio-cultural atmosphere functions as a mechanism that contributes to these outcomes, allowing me to assess arguments in the literature about how cultural norms in neighborhood or school contexts shape these outcomes (Fordham and Ogbu 1986; Massey and Denton 1993; Ogbu 1991; Portes and Zhou 1993; Wilson 1987, 1996). All along I take individual level factors seriously. For instance, research shows parent socioeconomic status, having a mentor and having been expelled from school are strong predictors of these outcomes. Finally, this paper addresses if contextual factors help explain racial/ ethnic disparities.

\section{The Data}

I use data from the National Longitudinal Study of Adolescent Health (Add Health) and supplemental data from the Adolescent Health and Academic Achievement (AHAA) study to conduct this analysis. The design of this study is such that a random sample of high schools and some of their feeder middle schools were selected during Wave 1 in 1994-1995 ( $\mathrm{N}=132)$. During Wave 1 all students in these schools, grades 7th-12th, answered a "student questionnaire" $(\mathrm{N}=90,000)$. Next, a sub-sample of students in Wave I was chosen for the longitudinal design of the study and these were followed into young adulthood in Wave III (2001-2002) when most were between the ages of 18 and $26(\mathrm{~N}=15,170)$. The average age for the sample at Wave III was 22. This sub-sample received an "in-home" interview during each wave and their parents were also interviewed during Wave I.

AddHealth is an appropriate dataset for this analysis because it contains both neighborhood and school level information. The dataset has contextual information collected for each respondent in the longitudinal sub-sample that includes 1990 census tract information for the neighborhood in which they lived in Wave 1. In addition, AddHealth is linked to and supplemented by the AHAA Study which provides secondary school level data, as well as transcript data that allows for academic controls, such as grade point averages. Racial and ethnic composition school variables are secondary data that come from the Common Core of Data (CCD) survey and the Private School Survey (PSS). Both of these surveys are implemented by the U.S. Department of Education's National Center for Education Statistics. 


\section{Measures}

There are two outcomes of interest, being a high school dropout and being a disconnected young adult. Dropouts were defined as participants who had not attained any degree by Wave III. Disconnected young adults were defined as respondents not in school, working or enrolled in the military. I focus on these two outcomes as indicators of an unsuccessful transition into adulthood given that both are associated with higher odds of being poor later in life.

Several racial and ethnic groups are identified in this study. Given concern that the high dropout rates of Latinos are indicators of "downward assimilation" (Portes and Zhou 1993), this study breaks down the Latino-origin group across nationality and generational status. Respondents who identified at WIII as Hispanic fell into one of five categories: Mexican-origin, Cuban, Puerto Rican, South or Central American, and Other Hispanic, mainly those who had mixed national origin backgrounds. Parents were identified as being either foreign born or U.S. born using parent and respondent data at Wave III (about $90 \%$ of the time this parent was the mother). Respondents were identified as first generation if they reported to be foreign born with a foreign born parent, second generation if they were U.S born with a foreign born parent and third-generation-plus if they were U.S. born with U.S. born parents. Given that foreign born respondents were attending school in Wave I, they are best characterized as 1.5 generation, immigrants who arrived young enough to enroll in U.S. schools and not those who migrated in search of work. Non-Hispanic respondents were identified as either being White (the reference group), Black, Asian-Pacific Islander or Native American. ${ }^{1}$

Key variables of interest are neighborhood level variables, specifically measures of socioeconomic status of the neighborhood and racial and generational composition. In line with other studies, I use the proportion of adults age 25 or older who are college graduates in the neighborhood as a measure of socioeconomic status of a neighborhood. ${ }^{2}$ I also examine the proportion of immigrants and proportion of blacks in the neighborhoods as key predictors given arguments that immigrant concentration may be "protective" and neighborhoods with high proportions of native US born minorities may be detrimental (Portes and Zhou 1993). Further, I control for residential stability and median age at the neighborhood level. Residential instability has long been found to be associated with poor life outcomes and the literature suggests that the proportion of youth in a neighborhood or the ratio of adults to youth may be important characteristic of a neighborhood to consider. All these neighborhood variables were measured at Wave 1 only.

\footnotetext{
${ }^{1}$ Those who reported to be racially mixed were asked to identify the racial group to which they most closely identified.

${ }^{2}$ I also conducted separate analyzes using the proportion of poor individuals in the neighborhood as a measure of socioeconomic status. Doing so did not alter the results. I opted not to present these results because proportion poor in the neighborhood is moderately correlated (.54) with proportion Black in the neighborhood and I wanted to disentangle these compositional effects to address theoretical arguments. I found proportion poor in the neighborhood was significantly related to both outcomes. However, once the school context was taken into account in the three level models, proportion poor was no longer significant, suggesting school contexts mediate neighborhood SES.
} 
I examine several school context characteristics. First, I examine whether the racial and ethnic composition of a school, namely proportion Latino and proportion Black, is associated with the outcomes of interest. Regrettably, school data is not disaggregated by generational status and I am unable to examine if immigrant concentration in the school is associated with these outcomes. However, I am able to control for whether the school was a public or private institution and the size of the school. ${ }^{3}$ These data are also derived from Wave 1.

In addition, using the Wave I "student questionnaire," two school level composites were constructed by aggregating individual level data collected of all students to the school level: the average sense of social incorporation and the average sense of disengagement among the student population. These composites were constructed to test if the socio-cultural atmosphere of schools was associated with these outcomes. The school integration scale was constructed with the following four questions, answered by students on a scale of 1-5: (a) I feel close to the people at this school; (b) I feel like I am part of this school; (c) I am happy to be at this school; and (d) I feel safe in my school. Similarly, the school disengagement scale was constructed with the following four questions: Since school started this year, how often have you had trouble (a) getting along with your teachers; (b) paying attention in school; (c) getting your homework done; and (d) getting along with other students?

Finally, several individual-level measures were tested as possible predictors and controls. These included variables known to be strongly associated with education and work-related outcomes, such as age, gender, parental socioeconomic status and family structure. Missing values were mostly an issue for parental income and to a less extent parental education. To address these missing individual-level variables, five imputed datasets were used for this study. Academic performance measures used in this analysis included the overall grade point average in year 1, the math level course at year 1 and a scholastic aptitude test at Wave I. The Peabody Picture Vocabulary Test (PPVT) is a commonly used test to measure scholastic aptitude and was used in the AddHealth study. ${ }^{4}$ In addition, two additional individual measures were examined as possible predictors, whether the respondent reported to have a mentor growing up and whether he/she was expelled from school at any time. No imputation was conducted for the neighborhood, school level or transcript variables.

\section{Methods}

The data is hierarchically clustered, individuals (level 1) are nested in neighborhoods (level 2) and neighborhoods feed into schools (level 3). Figure 1 presents a visual representation of these models (Appendix 1 provides the equation). A total of

\footnotetext{
${ }^{3}$ I considered using a measure of free-lunch at the school to gauge its socioeconomic composition but these data were missing for a lot of the schools.

${ }^{4}$ The PPVT was designed for native English-learners. For this reason, it is difficult to assess how much of this measure accounts for scholastic aptitude, English language proficiency or something else related to academic achievement. Due to the importance of controlling for academic performance, respondents without transcript data were dropped from the analysis.
} 
8,957 respondents (level 1), from 1,474 neighborhoods (level 2) who attended one of 79 high schools (level 3) were examined in this study. ${ }^{5}$ The data were fitted into multi-level Hierarchical Generalized Linear (HGLM) models given that both outcomes of interest are binary (HLM 6.0) (Raudenbush and Bryk 2002). Therefore, I test for the odds of dropping out or the odds of being disconnected at Wave III. Population sample weights were used in this analysis.

I conduct two separate types of analyzes. First, a two-level analysis examining individual and neighborhood effects was conducted for each outcome (Neighborhood-Only models). This is the kind of analysis conducted by most studies examining neighborhood effects whereby schools as institutions are not taken into account. Two-level unconditional fitted models (not shown) suggest that there is significant variation across neighborhoods for each outcome. Second, a three-level analysis was conducted examining the relevance of individual, neighborhood and school context effects for each outcome (Neighborhood and School models). The results of the three-level unconditional models (not shown) suggest that while there is significant variation across schools, there is no significant variation across neighborhoods. I discuss how introducing the school context into the analysis alters the results. Comparing the first set of models (neighborhood-only) to the second set of models (neighborhood and school), I am able to examine if neighborhood effects are mediated by school context characteristics. The same sample is used when comparing the two-level and three-level models.

\section{Findings}

One major motivation for conduction neighborhood and school effect studies centers on the overrepresentation of racial and ethnic minority groups in these contexts and their higher rates of poor life outcomes. Appendix 2 provides descriptive characteristics of the variables examined by race and ethnicity as way to present how these groups experience contexts differently. Here, I begin by highlighting notable descriptive characteristics that capture racial/ethnic disparities in these outcomes. Consistent with established research, Table 1 shows Black and specifically Mexican-origin young adults' exhibit high rates of high school noncompletion, 8 percent and 13 percent respectively. However, Latinos are not overrepresented among the disconnected. About $11 \%$ of young adults fall into the disconnected group category and Latinos reflect this general pattern, despite having the highest dropout rate. In fact, while the 1.5 generation Mexican group has the highest percentage of high school dropouts $(18 \%)$, it is also the group with the lowest percentage of disconnected young adults $(8 \%)$.

These descriptive statistics highlight that the dropout and disconnected young adult populations are not necessarily the same, at least for the Mexican-origin group and specifically for children of immigrants. Evidently some high school dropouts' return to school for their diploma and some are firmly attached to the labor market.

\footnotetext{
5 Add Health sampled high schools and at times their feeder middle schools. This type of school sampling meant that not all respondents were hierarchically nested. To simplify the analysis I examined only respondents who were in high school in Wave I and dropped those who were in middle school then.
} 


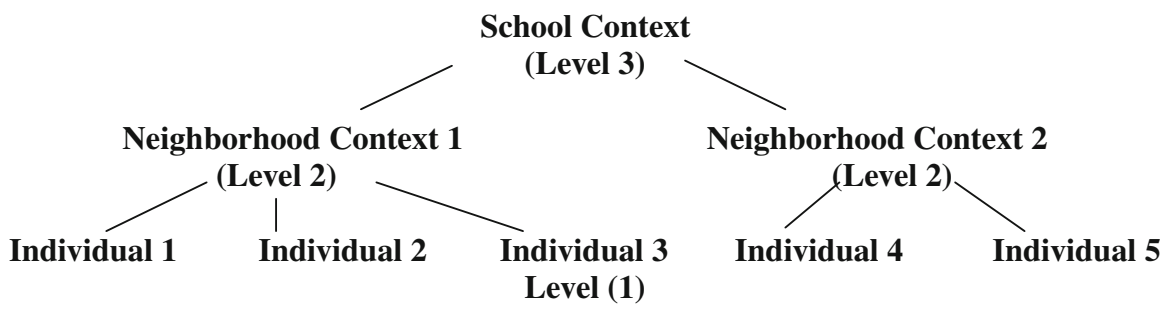

Fig. 1 Hierarchical model

Table 1 Racial/ethnic groups and outcomes (percent)

Source: National Longitudinal Study of Adolescent Health (Add Health)

\begin{tabular}{lcc}
\hline & HS dropout & Disconnected \\
\hline White & 5 & 11 \\
Black & 8 & 15 \\
Asian & 4 & 11 \\
Latino & 11 & 11 \\
Mexican-origin & 13 & 12 \\
1.5 Generation Mexican & 18 & 8 \\
Second generation Mexican & 13 & 12 \\
Third generation Mexican & 11 & 15 \\
Total & 6 & 11 \\
\hline
\end{tabular}

On the other hand, some high school graduates are among those who are disconnected from school and work in their young adult years. As Table 1 shows, Blacks and third-generation Mexican-Americans have a higher than average proportion of disconnected young adults. ${ }^{6}$ To the extent that being detached from school and work reflects a more serious degree of disadvantage than being a high school dropout, these U.S. born native minority groups stand out as being particularly at-risk.

In what follows I present the results for the multi-level model analyses. I present the results for the odds of dropping out in Table 2 and for the odds of being disconnected in Table 3. In light of the descriptive statistics, I begin by drawing attention to racial and ethnic disparities in these outcomes. I then present the results for the two-level ("Neighborhoods Only") models and discuss neighborhood effect results. In doing so, I draw attention to whether racial and ethnic disparities are altered by accounting for neighborhoods contextual measures once other individuallevel factors are controlled. I then repeat these steps in the three-level model by taking into account the school context ("Neighborhoods and School"). I discuss how introducing the school context into the analysis alters the results, again, drawing attention to how these contextual factors alter racial and ethnic disparities in these outcomes.

\footnotetext{
${ }^{6}$ Blacks with higher levels of socioeconomic status were oversampled in AddHealth. Weights used do not adjust for this. Readers should be cautious about interpretations made concerning this group. It is likely that the average dropout and disconnected figures are actually higher than the data suggest.
} 
Table 2 Neighborhoods versus school and neighborhoods on the odds of dropping out

\begin{tabular}{|c|c|c|c|c|c|c|}
\hline & \multicolumn{3}{|c|}{ Neighborhood only } & \multicolumn{3}{|c|}{ Neighborhood and school context } \\
\hline & 1 & 2 & 3 & 4 & 5 & 6 \\
\hline Mexican & $2.56 * *$ & $2.50 * *$ & 1.20 & $2.42 * *$ & $2.45^{*}$ & 1.16 \\
\hline Cuban & 0.96 & 0.60 & 0.85 & 0.90 & 0.97 & 1.27 \\
\hline Mixed Latino & 1.31 & 1.30 & 0.82 & 1.36 & 1.36 & 0.82 \\
\hline Puerto Rican & 0.58 & 0.62 & 0.28 & 0.60 & 0.60 & 0.29 \\
\hline Central American & 1.57 & 1.58 & 0.80 & 1.66 & 1.65 & 0.84 \\
\hline Black & 1.24 & 1.26 & $0.63 *$ & 1.23 & 1.24 & $0.62 * *$ \\
\hline Native & 1.55 & 1.55 & 0.54 & 1.47 & 1.48 & 0.52 \\
\hline Asian & 1.01 & 0.99 & 1.04 & 0.91 & 0.92 & 0.96 \\
\hline Female (vs. male) & $0.59^{*}$ & $0.58^{*}$ & 0.86 & $0.58^{* *}$ & $0.58 * *$ & 0.84 \\
\hline Age & 0.97 & 0.97 & $0.94 *$ & 0.97 & 0.97 & 0.92 \\
\hline First generation & 1.10 & 1.09 & 1.16 & 1.13 & 1.12 & 1.07 \\
\hline Second generation & 0.95 & 0.95 & 1.02 & 0.95 & 0.94 & 1.01 \\
\hline Single parents & & & 0.89 & & & 0.90 \\
\hline Parent education & & & $0.88 * *$ & & & $0.87 * *$ \\
\hline Parent income (logged) & & & 0.86 & & & 0.86 \\
\hline Parent on public assistance & & & $2.12 * *$ & & & $2.00 * *$ \\
\hline GPA & & & $0.38 * *$ & & & $0.37 * *$ \\
\hline Math level at year 1 & & & $0.87 * *$ & & & $0.87 * *$ \\
\hline AH_PVT & & & $0.97 * *$ & & & $0.97 * *$ \\
\hline Mentor & & & $0.61 * *$ & & & $0.60 * *$ \\
\hline Expelled & & & $3.72 * *$ & & & $3.61 * *$ \\
\hline \multicolumn{7}{|l|}{ Neighborhood context } \\
\hline Prop. immigrant & & 1.65 & 1.83 & $3.16^{*}$ & $3.13^{*}$ & $4.26^{*}$ \\
\hline Prop. Black & & 0.96 & 1.00 & 0.86 & 0.85 & 0.84 \\
\hline Prop. college graduates & & $0.30 * *$ & $0.22 * *$ & 0.77 & 0.82 & 0.80 \\
\hline Residential Stability & & 2.30 & 2.44 & 1.09 & 1.08 & 1.20 \\
\hline Median age & & $0.92 * *$ & $0.89 * *$ & $0.94 *$ & $0.94 *$ & $0.92 * *$ \\
\hline \multicolumn{7}{|l|}{ School context } \\
\hline School size & & & & & $0.72^{*}$ & $0.66^{*}$ \\
\hline Prop. Hispanic & & & & & $2.46^{*}$ & $3.92 * *$ \\
\hline Prop. Black & & & & & $3.21^{*}$ & $4.09 * *$ \\
\hline School type & & & & & $0.13^{* *}$ & $0.17^{* *}$ \\
\hline School incorporation & & & & & 0.87 & 0.93 \\
\hline School engagement & & & & & 0.92 & 0.89 \\
\hline
\end{tabular}

The results above are odds ratios ** > .01; * > .05 
Table 3 Neighborhoods versus school and neighborhoods on the odds of being disconnected

\begin{tabular}{|c|c|c|c|c|c|c|}
\hline & \multicolumn{3}{|c|}{ Neighborhood only } & \multicolumn{3}{|c|}{ Neighborhood and school context } \\
\hline & 1 & 2 & 3 & 4 & 5 & 6 \\
\hline Mexican & 0.77 & 0.77 & $0.59 *$ & 0.78 & 0.78 & 0.59 \\
\hline Cuban & 0.81 & 0.71 & 0.64 & 0.65 & 0.65 & 0.61 \\
\hline Mixed Latino & 0.88 & 0.89 & 0.78 & 0.91 & 0.91 & 0.80 \\
\hline Puerto Rican & 1.43 & 1.44 & 1.25 & 1.40 & 1.40 & 1.18 \\
\hline Central American & 1.19 & 1.19 & 1.00 & 1.18 & 2.18 & 0.99 \\
\hline Black & $1.68 * *$ & $1.69 * *$ & $1.43 * *$ & $1.66^{*}$ & $1.66^{*}$ & 1.41 \\
\hline Native & 0.57 & 0.57 & 0.41 & 0.57 & 0.57 & $0.42 *$ \\
\hline Asian & 1.50 & 1.49 & 1.60 & 1.50 & 1.48 & 1.59 \\
\hline Female (vs. male) & $1.34 * *$ & $1.34 * *$ & $1.61 * *$ & $1.34 *$ & $1.34 * *$ & $1.61 * *$ \\
\hline Age & 1.05 & 1.05 & 1.04 & 1.05 & 1.05 & 1.04 \\
\hline First generation & $0.60 * *$ & $.59 * *$ & $.66^{*}$ & $0.58 * *$ & $0.58 * *$ & $0.65^{*}$ \\
\hline Second generation & 1.29 & 129 & $1.37 *$ & 1.28 & 1.29 & 1.37 \\
\hline Single parents & & & 0.83 & & & 0.84 \\
\hline Parent education & & & 0.97 & & & $0.98 * *$ \\
\hline Parent income (logged) & & & 0.91 & & & 0.91 \\
\hline Parent on public assistance & & & $1.42 *$ & & & $1.39 *$ \\
\hline GPA & & & $0.68 * *$ & & & $0.68 * *$ \\
\hline Math level at year 1 & & & 0.95 & & & 0.94 \\
\hline AH_PVT & & & 1.00 & & & 1.00 \\
\hline Mentor & & & 0.84 & & & $0.84 *$ \\
\hline Expelled & & & $1.85 * *$ & & & $1.79 * *$ \\
\hline \multicolumn{7}{|l|}{ Neighborhood context } \\
\hline Prop. immigrant & & 0.90 & 0.89 & 1.06 & 1.05 & 1.04 \\
\hline Prop. Black & & 1.06 & 1.06 & 1.07 & 1.03 & 1.04 \\
\hline Prop. college graduates & & 0.92 & 0.97 & 0.62 & 0.65 & 0.64 \\
\hline Residential stability & & 1.37 & 1.44 & 1.19 & 1.19 & 1.17 \\
\hline Median age & & $0.96 *$ & $0.96 * *$ & $0.97 * *$ & $0.97 * *$ & $0.97 * *$ \\
\hline \multicolumn{7}{|l|}{ School context } \\
\hline School size & & & & & $0.78 *$ & $0.78 *$ \\
\hline Prop. Hispanic & & & & & 1.15 & 1.18 \\
\hline Prop. Black & & & & & $2.44^{*}$ & $2.43 *$ \\
\hline School type & & & & & $0.52 * *$ & $0.55 * *$ \\
\hline School incorporation & & & & & 0.89 & 0.89 \\
\hline School engagement & & & & & 0.99 & 0.98 \\
\hline
\end{tabular}

The results above are odds ratios $* *>.01 ; *>.05$ 


\section{Multi-Level Analyses for the Odds of Dropping Out}

Table 2 is divided into two separate columns. The first column shows models 1-3. These are the results for the two-level analysis that test for neighborhood effects without accounting for the school context ("Neighborhoods Only"). In the first model, only racial and ethnic variables are examined. These results show that Mexican-Americans have 2.5 higher odds of dropping out relative to whites, consistent with descriptive statistics. The second model then accounts for the neighborhood context. I find that neighborhood SES is significantly associated with dropping out; a $1 \%$ increase in college graduates in a neighborhood is associated with .30 lower odds of dropping out. The only other neighborhood characteristic found to be significant is median age; the higher the median age in a neighborhood, the lower the odds of dropping out. Importantly, controlling for neighborhood characteristics does not affect racial and ethnic disparities on the likelihood to dropout, suggesting other factors matter.

The following model (3) includes neighborhood and all individual level characteristics. This model shows that neighborhood SES remains significant after adding all individual-level controls, suggesting there is something beneficial about living in high SES neighborhoods that lowers the odds of dropping out, regardless of respondents' background characteristics. Importantly, once individual background characteristics are controlled, Mexican-Americans no longer display higher odds to dropout relative to whites.

The second column in Table 2 shows models 4-6. These models assess if neighborhood characteristics are associated with the odds of dropping out, while taking into account school context characteristics ("Neighborhood and School Context"). Model 4 fits the data into a three-level model, controlling only for race/ ethnicity, gender, age and generational status, as well as, neighborhood characteristics. Fitting the data into the three-level model alters the results in important ways from the two-level (Neighborhood only) model. Doing so shows that neighborhood SES is no longer significantly associated with dropping out. Instead, the data show that a higher proportion of immigrants in a neighborhood is associated with dropping out. This relationship is strengthened when family background and academic controls are added to the model (6), suggesting that the immigrant context is not protective or helps students graduate; instead the opposite appears to be the case.

Model 5 in Table 2 adds school context variables into the model. These results suggest that what matters is not the SES composition of neighborhoods, but rather the composition of schools that youth attend. Consistent with other research, the data show that attending a private school is associated with lower odds of dropping out. Furthermore, attending a school with a higher percentage of Latino and Black students increases the odds of dropping out. When family and academic controls are added in Model 6, these school effects are further strengthened. The findings are consistent with education research which shows that schools with large numbers of Latino and Black students or highly segregated school contexts are associated with poor education outcomes. 
These data, however, cannot explain why attending a school with large numbers of Latino or Blacks would increase the odds to dropout. One possible mechanism proposed in the literature is the idea that an "oppositional culture" in urban contexts drives poor youth outcomes (Ogbu 1991; Portes and Zhou 1993; Wilson 1987). I assess this theoretical possibility by examining the social-cultural atmosphere for the high schools young adults attended. High schools that reported a low level of social integration or social engagement were treated as schools with a presence of an oppositional culture. However, the socio-cultural scales used in this analysis were not found to be significant. To the extent that these composites accurately account for an oppositional culture, the findings suggest it is not one of the mechanisms that contribute to dropping out.

Model 6 (like Model 3) shows individual-level factors significantly associated with dropping out in the expected direction. Interestingly, neither parental income nor family structures were found to be significant. Yet this final model does identify two additional factors associated with dropping out. One of these is school expulsion, which increases the odds of remaining a high school dropout in young adulthood by roughly three and a half times. Expulsion further explains why young men are more likely to dropout relative to females. That is, once expulsion is taken into account, there is no longer a significant gender difference. Second, having a mentor is associated with .60 lower odds of dropping out, suggesting role models or social capital improves educational outcomes.

Finally, the analyses indicate that neither controlling for the school or neighborhood context reduces the odds of dropping out for Mexicans relative to whites. Instead, as other studies have found, low parental education and poor academic performance (GPA measured in Wave I, 9th grade) explains the groups' higher odds to dropout. Only after controlling for these variables does the significant difference between Mexicans and whites disappear (models 3 and 6). While immigration researchers emphasize generational differences in outcomes among ethnic groups, I do not find that generational status was significantly related to dropping out, including for the Mexican-origin group (interactions not shown).

\section{Multi-Level Analyses for the Odds of Being Disconnected}

Table 3 is also divided into two separate columns. Again, the first column fit the data into two-level models (1-3) and examine if neighborhoods are associated with the odds of being disconnected without accounting for the school context ("Neighborhoods Only"). The second column shows models 4-6 which fit the data into three-level models and incorporates the school context into the analysis ("Neighborhood and School Context").

I begin by testing if racial/ethnic variables, gender, age and generational status are associated with being disconnected in Model 1. Consistent with the descriptive statistics, the results show that Blacks have 1.68 higher odds of disconnected compared to whites and the first generation has .60 lower odds of being disconnected compared to the third generation. Model 2 then examines neighborhood contextual factors on the likelihood to be disconnected. These results show 
there are no significant neighborhood effects on the odds of being disconnected in the young adult years. Only median age of the neighborhood was found to be significantly related to this outcome; a higher median age in the neighborhood is associated with lower odds of being disconnected.

Model 3 adds all individual level-controls in the two-level model. Here, I find having a parent on public assistance increases the odds to be disconnected by 1.42 . Having a high GPA lowers the odds of being disconnected while having been expelled almost doubles these (1.85). In addition, controls alter other findings. These data show that the second-generation is associated with higher odds of being disconnected, while being Mexican-American is associated with lower odds of being disconnected.

However, as models 4-6 show, results on the likelihood to be disconnected change significantly when the data is fitted into the three-level model and the school context is taken into account. In this case, I still find no significant association between the neighborhood factors and this outcome, other than a higher median age in the neighborhood being associated with lower odds of being disconnected.

Yet there are statistically significant school effects. For instance, attending a private school is associated with half the odds of being disconnected, whereas an increase in the proportion of Black students in school is associated with higher odds of being disconnected (model 5). These school context effects remain significant after controlling for all individual controls (model 6), suggesting there is something detrimental about schools with high proportions of Blacks that contribute to this problem, regardless of individuals' background. Regrettably, these data are unable to explain why these schools increase the odds of being disconnected. I examined if the socio-cultural atmosphere of schools was associated with this outcome, but found no significant impact.

Importantly, the full three-level model (6) indicates that racial/ethnic and generational disparities on being disconnected are sensitive to the school context. Prior to full three-level model (6), the results showed that Blacks experienced roughly one and half times higher odds of being disconnected relative to whites (see models 1-5). The data show that neighborhood compositional characteristics did not explain this racial disparity. However, once individual and school context factors are taken into account the significant difference between Blacks and whites disappears. Specifically, Blacks' higher odds of being disconnected is attributed to their family background, such as being on public assistance, their lower academic performance relative to whites and the types of schools they attend. These results communicate that school context characteristics impact not only educational outcomes, but work-related patterns in the young adult years, contributing to racial inequalities.

The concentrations of Latinos, specifically Mexican-Americans, in specific types of schools also explain earlier observations. The full two-level model (3) showed that Mexicans have .59 lower odds of being disconnected compared to whites of similar backgrounds, living in similar kinds of neighborhoods. Yet the final threelevel model shows that this advantage relative to whites disappears once the school context is taken into account (models 4-6). That is, schools negatively affect the Mexican-origin group by curbing their advantage because the schools they attend, 
on average, are associated with higher odds of being disconnected compared to the schools whites attend, on average. The final three-level model (6) also now shows no significant higher odds of being disconnected for the second-generation, as compared to the two-level model. Again, this suggests that the greater odds of being disconnected observed in the two-level models for the second generation was driven mainly by school context factors. Interestingly, the data show that even after controlling for all individual, school and neighborhood factors, first generation individuals still have significantly lower odds of being disconnected in the young adult years. That is, foreign born children of immigrants have a stronger attachment to either school or work compared to the US born population, regardless of the neighborhood or school context.

Finally, consistent with the dropout results, two additional factors stand out as being particularly strong predictors. Having a mentor significantly lowers the likelihood to be disconnected by.84, attesting to the positive impact of resourceful ties in adolescence. On the other hand, having been expelled from school increases the odds to be disconnected in young adulthood by 1.79 higher odds.

\section{Discussion and Conclusion}

Young adults without a high school degree and those disconnected from school and work are among the most vulnerable to making an unsuccessful transition into adulthood. It has been observed that these poor school and work-related outcomes concentrate in less advantaged neighborhoods and particularly affect racial and ethnic minority groups. The results of this study demonstrate that to understand how neighborhood contexts contribute to these outcomes and racial and ethnic disparities, it is important to account for its schools.

Schools remain a primary institution of neighborhoods. Yet there remains minimal understanding and theorizing about how neighborhoods and schools interact to produce various life outcomes. A review of the literature shows a great disconnect between scholars who examine school contexts and those who examine neighborhood contexts. The results in this study begin to show why this disconnect is problematic. Not only do neighborhood effect results change upon entering school context factors into the analysis, but these changes point to underlying social processes in and between schools and neighborhoods not well understood. This calls for qualitative researchers to identify and examine the social processes that link neighborhoods and schools and for quantitative researchers to pursue datasets that allow them to do similar work.

One of the most consistent neighborhood effects findings in the literature is that the socioeconomic status of a neighborhood is associated with various life outcomes, including the odds of dropping out (Clark 1992; Crane 1991; Ensminger et al. 1996; Harding 2003). While there is strong empirical support for this relationship, it is still unclear what neighborhood mechanisms contribute to such outcome. Some scholars have suggested that perhaps socialization or information exchange in higher SES neighborhoods is what produces higher educational outcomes (Ainsworth 2002). In this study, neighborhood SES becomes no longer 
significant after accounting for school factors. Instead I find school compositional characteristics, namely a higher proportion Latino and Black students, to be significantly associated with dropping out. These results suggest that the impact neighborhood SES has on dropping out is indirect and mediated through the school context and closely aligned with its racial and ethnic composition and unexamined related dynamics. In general, the finding is consistent with school-effect studies that repeatedly show schools with a high proportion of Latino and Blacks students-or highly segregated school contexts-are associated with poor educational outcomes (Rumberger 2011). Yet it adds to the existing body of work by pointing to a relationship that exists between neighborhood SES and the racial and ethnic composition of schools that requires further exploration.

The literature also suggests that neighborhoods help explain why some individuals or groups are more likely to be disconnected from school or work than others (Wilson 1996). In this study, I find no empirical support for this argument, other than a neighborhood median age being associated with lower odds of being disconnected. Rather than finding significant neighborhood effects, again, I find school factors significantly associated with this outcome. Here, school effects do not mediate neighborhood effects but stand alone. Specifically, attending a school with a higher proportion of Black students increases the odds of being disconnected-not only for Blacks but other groups, like Mexicans or the second generation, as well. Cutler and Glaeser (1997) find support that neighborhood segregation contributes to an increase in "idleness" (being disconnected). Yet, to my knowledge, no other studies have documented an association between school racial composition and this outcome, leaving ample room for theorizing and further research.

In general, the finding that schools context factors are more directly associated with these outcomes perhaps should not be too surprising considering most youth spend most of their time in schools rather than neighborhoods per se. Further, schools accentuate segregation and inequality across neighborhood. Research shows that better-off residents often opt to enroll their children in private or more select schools, such as charter or magnet schools, leaving behind the most disadvantaged students in neighborhood schools. Therefore, it is not surprising that disparities across racial/ethnic and generational groups were sensitive to school context factors. For example, when considering these outcomes among the second generation or Latinos - an area of great concern among scholars suggesting possible "second generation decline" - these results show it is necessary to account for the kinds of schools these students attend, in addition to the neighborhoods in which they concentrate. In their research, Portes and MacLeod (1996) and Pong and Hao (2007) also find school compositional factors to be associated with poor outcomes among children of immigrants. These studies suggest that schools are a key institution shaping the integration process for children of immigrants.

Yet this study leaves unclear exactly what mechanisms in racial and ethnic majority schools increase the odds to dropout or be disconnected in young adulthood. One hypothesis examined was the idea that students influence one another through norms, aspirations and expectations and that certain school contexts have social-cultural atmospheres that contribute to poor educational outcomes (Fordham and Ogbu 1986; Ogbu 1991; Portes and Zhou 1993; Wilson 1987). To the 
extent that social-cultural measures in this study effectively served as a proxy for an "oppositional culture," I find no empirical support for this argument. This is consistent with ample body of work which finds no support for an oppositional culture being the mechanism underlying poor educational outcomes, including for urban predominantly minority schools (Ainsworth-Darnell and Downey 1998; Carter 2005; Cook and Ludwig 1998; Downey et al. 2009; Flores-Gonzalez 2002; Harding 2010; Harris 2011; Mateu-Gelabert and Lune 2007; Solorzano 1992; Tyson et al. 2005; Warikoo 2011).

There are, of course, alternative explanations for why attending schools with large numbers of Blacks and Latinos would increase the chances to dropout or be disconnected in young adulthood. Education researchers have documented important resource inequities across schools, including differences in the quality and training of teachers, academic rigor and course offerings (Orfield and Lee 2005). One specific limitation of this study is not controlling for the socioeconomic status of the school, a possible competing factor. Future research should also consider how neighborhoods interact with schools. In this study, being expelled from school was a strong predictor for dropping out and to become disconnected. Research could examine expulsion not as individual factor, but rather a school policy or approach that may differ across schools and neighborhoods. That is, one way neighborhoods and schools may interact is if schools respond differently to school discipline issues depending on the neighborhood context. This study examined if schools mediated neighborhood effects. Yet it could also be that either the school or neighborhood context ameliorate or exacerbate contextual effects. Neighborhood conditions can impact school dynamics in significant ways. In their research, Card and Rothstein (2007) found that more integrated neighborhoods resulted in higher within-school segregation, in essence cancelling any positive impacts of neighborhood integration. Clearly, more research is needed to better understand the school mechanisms or social processes contributing to these outcomes. Similar research is needed to better understand how the neighborhood and school contexts interact.

While findings in this study highlight the importance of accounting for school factors when conducting neighborhood effect research, the results do not necessarily indicate neighborhoods are irrelevant. Like others, this study has several limitations. First, only a few neighborhood contextual factors were examined making it possible that other neighborhood factors - like neighborhood disadvantage or urban violence (see Burdick-Will et al. 2011; Harding 2010; also see Sharkey 2010)—may contribute to these outcomes as suggested in some studies. Second, like other studies relying on census tract data, this study was constrained in its ability to assess neighborhood mechanisms or social processes. Researchers are encouraged to seek alternative datasets specifically designed to study neighborhood processes.

Even with these limitations, the study does draw attention to two specific neighborhood characteristics less discussed in the literature. First, results show that living in neighborhoods with a higher median age reduces the likelihood that young adults will be dropouts or disconnected. A higher median age means fewer youth in these neighborhoods relative to adults or simply a neighborhood with a stronger presence of an older population. This can translate to more social control in the neighborhood that deters youth from engaging in behaviors that associated with 
dropping out or being disconnected. Alternatively, more adults in the neighborhood could also produce a more resourceful environment where role models or mentors are easier to find. Though the age structure in a neighborhood has not been completely ignored in the literature (Harding 2010), it typically does not get attention as being as important as other neighborhood characteristics. Yet these results suggest this should be examined further, particularly as one way to understand disparities across racial and ethnic groups. Demographic trends show racial and ethnic minorities have a lower median age relative to whites who have an aging population. Inevitably this different age structure is reflected across neighborhoods.

Further, this study shows that living in neighborhoods with higher rates of immigrants is significantly associated with dropping out. Immigration researchers have argued that certain immigrant groups have weak ethnic ties and lack social capital that could produce such outcomes (Portes and Rumbaut 2001; Portes and Zhou 1993). More empirical research is needed to determine why immigrant concentration is detrimental for educational attainment above and beyond individual factors (Pong and Hao 2007). Yet it could be that living in a neighborhood with large numbers of adults who lack information and resources, including cultural understanding of the American educational system, negatively impacts educational attainment for all. For instance, in such immigrant neighborhoods, school personnel or educators may likely be less responsive to this group, negatively impacting the schooling process for all its youth (see Noguera 2003).

Finally, this study highlights the need to seriously examine how neighborhood and school contexts impact groups and outcomes differently. For instance, Latinos, specifically the Mexican-origin group, and Blacks experience different challenges as they transition into adulthood: Mexicans are more likely not to complete high school compared to all other groups, whereas Blacks most likely to be disconnected. How neighborhoods or schools are shaping the outcomes for these two groups may differ. It's possible that some neighborhood or school social processes may matter more for some groups than others. For instance, urban violence in a neighborhood may be particularly detrimental for education and work-related outcomes for young men as compared to females in these neighborhoods (Harding 2010). Similarly, more theoretical or conceptual work is needed as to why neighborhoods would contribute to specific outcomes, for example, dropping out of high school versus low academic achievement, or why school contexts may contribute to being disconnected. The results from these analyses should remind researchers to carefully consider the outcomes in question.

This study was motivated by the challenging transition to adulthood faced by many individuals, particularly racial and ethnic minorities that concentrate in less advantaged neighborhoods. This study shows that one significant way in which neighborhoods shape young adult outcomes is through its schools. This study suggests policy makers and practitioners interested in promoting a successful transition to adulthood should consider school targeted interventions as a way to address these issues. Yet researchers need to continue their efforts to identify how neighborhood and school social processes interact to facilitate such interventions. 
Open Access This article is distributed under the terms of the Creative Commons Attribution License which permits any use, distribution, and reproduction in any medium, provided the original author(s) and the source are credited.

\section{Appendix 1: Full Model(s) Equation}

$$
\begin{aligned}
\log \left[\rho_{i j k} /\left(1-\rho-{ }_{i j k}\right)\right]= & \beta_{\text {ojk }}+\beta_{1} \text { Race }_{i j k}+\beta_{2} \text { Background }_{i j k}+\beta_{3} \text { Neighborhood }_{i j k} \\
& +\beta_{4} \text { School }_{i j k}+e_{i j k}+u_{j k}+\alpha_{k}
\end{aligned}
$$

where $\rho_{\mathrm{ijk}}$ is the probability that student $\mathrm{i}$ from neighborhood $\mathrm{j}$ from school $\mathrm{k}$ drop out of school or reports being disconnected. $\beta_{\mathrm{ojk}}$ is the intercept term, $\beta_{1}$ represents a vector of dummy racial/ethnic identity variables with whites being the omitted category, $\beta_{2}$ represents a vector of parameters associated family background, scholastic aptitude and other control variables, $\beta_{3}$ represents a vector of neighborhood variables, $\beta_{4}$ represents a vector of school level parameters. Finally, $\mathrm{e}_{\mathrm{ijk}}$, $\mathrm{u}_{\mathrm{jk}}$., $\alpha_{\mathrm{k}}$ are error terms associated with each level.

\section{Appendix 2}

See Tables 4, 5 and 6.

\begin{tabular}{|c|c|c|c|c|c|c|c|c|c|}
\hline & \multicolumn{9}{|c|}{ Individual background characteristics } \\
\hline & $\begin{array}{l}\text { Parental } \\
\text { education }\end{array}$ & $\begin{array}{l}\text { Parental } \\
\text { income }\end{array}$ & $\begin{array}{l}\text { Single } \\
\text { parent }\end{array}$ & Mentor & Expelled & $\begin{array}{l}\text { PVT } \\
\text { score }\end{array}$ & $\begin{array}{l}\text { Math level } \\
\text { year 1 } \\
\text { (scale 1-9) }\end{array}$ & $\begin{array}{l}\text { Overall } \\
\text { GPA } \\
\text { year } 1\end{array}$ & $\begin{array}{l}\text { Proportion } \\
\text { poor }\end{array}$ \\
\hline Black & 5.6 & 40.5 & 0.15 & 0.74 & 0.11 & 94.5 & 3.50 & 2.28 & 0.16 \\
\hline White & 5.8 & 54.4 & 0.02 & 0.79 & 0.06 & 105 & 3.78 & 2.73 & 0.14 \\
\hline Asian & 5.9 & 57.6 & 0.03 & 0.75 & 0.04 & 99 & 3.99 & 3.03 & 0.11 \\
\hline Hispanic & 3.9 & 40.2 & 0.05 & 0.68 & 0.08 & 93.9 & 3.28 & 2.34 & 0.13 \\
\hline $\begin{array}{l}\text { Mexican- } \\
\text { origin }\end{array}$ & 3.4 & 39.5 & 0.04 & 0.66 & 0.08 & 92.7 & 3.24 & 2.40 & 0.13 \\
\hline $\begin{array}{l}\text { First } \\
\text { generation } \\
\text { Mexican }\end{array}$ & 2.3 & 35.8 & 0.05 & 0.61 & 0.05 & 82.3 & 2.90 & 2.40 & 0.13 \\
\hline $\begin{array}{l}\text { Second } \\
\text { generation } \\
\text { Mexican }\end{array}$ & 2.6 & 35.1 & 0.03 & 0.65 & 0.07 & 92.7 & 3.33 & 2.45 & 0.12 \\
\hline $\begin{array}{l}\text { Third } \\
\text { generation } \\
\text { Mexican }\end{array}$ & 4.6 & 45.8 & 0.04 & 0.69 & 0.12 & 97 & 3.28 & 2.35 & 0.13 \\
\hline Overall & 5.4 & 49.2 & 0.05 & 0.76 & 0.07 & 100 & 3.65 & 2.60 & 0.14 \\
\hline
\end{tabular}

Table 4 Racial/ethnic groups: individual characteristics 


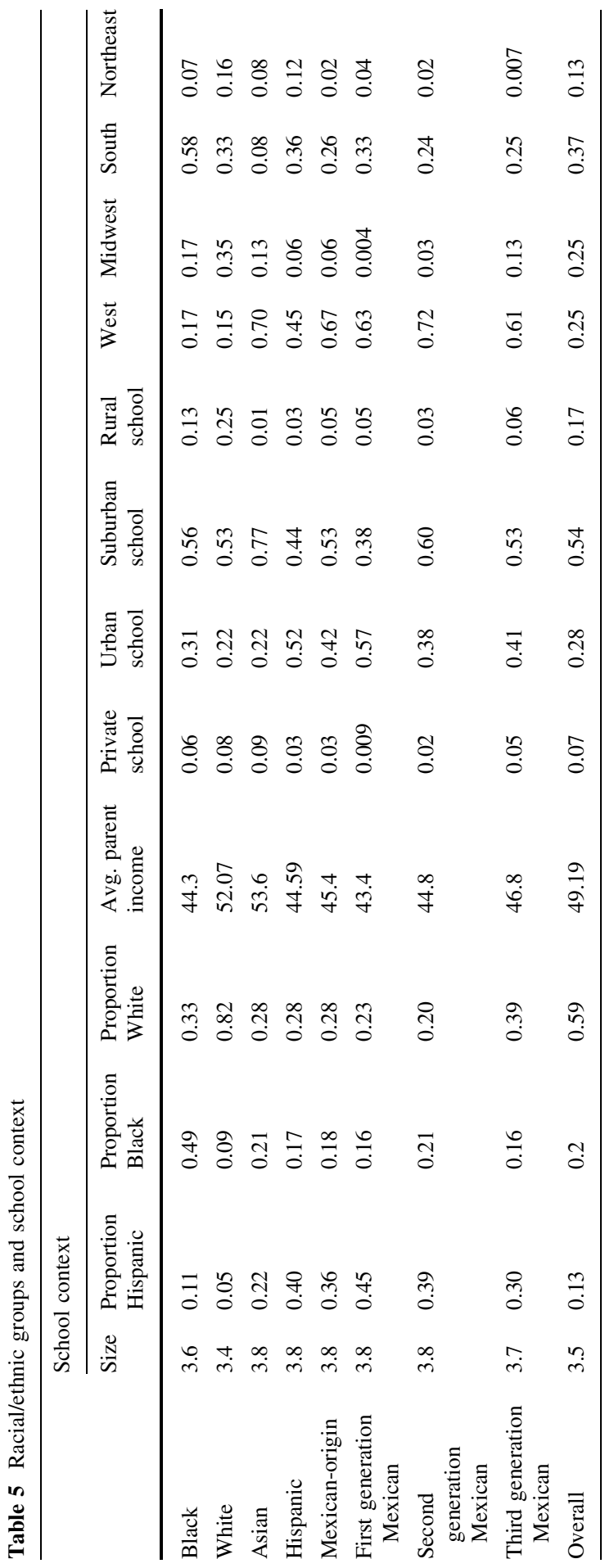


Table 6 Racial/ethnic groups and neighborhood

\begin{tabular}{lllll}
\hline & \multicolumn{2}{l}{ Neighborhood context } \\
\cline { 2 - 5 } & $\begin{array}{l}\text { Proportion } \\
\text { immigrant }\end{array}$ & $\begin{array}{l}\text { Proportion } \\
\text { Black }\end{array}$ & $\begin{array}{l}\text { Proportion college } \\
\text { graduates }\end{array}$ & $\begin{array}{l}\text { Proportion } \\
\text { poor }\end{array}$ \\
\hline Black & 0.09 & 0.21 & 0.22 & 0.16 \\
White & 0.08 & 0.16 & 0.22 & 0.14 \\
Asian & 0.16 & 0.13 & 0.25 & 0.11 \\
Hispanic & 0.14 & 0.14 & 0.24 & 0.13 \\
Mexican-origin & 0.15 & 0.14 & 0.24 & 0.13 \\
First generation Mexican & 0.15 & 0.14 & 0.23 & 0.13 \\
Second generation Mexican & 0.16 & 0.13 & 0.26 & 0.12 \\
Third generation Mexican & 0.14 & 0.15 & 0.24 & 0.13 \\
Overall & 0.1 & 0.16 & 0.23 & 0.14 \\
\hline
\end{tabular}

\section{References}

Ainsworth, J. W. (2002). Why does it take a village? The mediation of neighborhood effects on educational achievement. Social Forces, 81(1), 117-152.

Ainsworth-Darnell, J. W., \& Downey, D. B. (1998). Assessing the oppositional culture explanation for racial/ethnic differences in school performance. American Sociological Review, 63, 536-553.

Aneshensel, C. S., \& Sucoff, C. A. (1996). The neighborhood context and adolescent mental health. Journal of Health and Social Behavior, 37, 293-310.

Arum, R. (2000). Schools and communities: Ecological and institutional dimensions. Annual Review of Sociology, 26, 395-418.

Bennett, P. R. (2011). The relationship between neighborhood racial concentration and verbal ability: An investigation using the institutional resource model. Social Science Research, 40, 1124-1141.

Besharov, D. J. (1999). America's disconnected youth: Toward a preventive strategy. Washington, DC: CWLA Press.

Bond-Huie, S., Hummer, R., \& Rogers, R. (2002). Individual and contextual risk of death among race and ethnic groups in the United States. Journal of Health and Social Behavior, 43(3), 359-381.

Borman, G. D., \& Dowling, M. (2010). Schools and inequality: A multilevel analysis of Coleman's equality of educational opportunity data. Teachers College Record, 112(5), 1201-1246.

Briggs, X., Ferryman, K., Popkin, S., \& Rendón, M. (2008). Why didn't the moving to opportunity experiment get children to better schools? Housing Policy Debate, 19(1), 53-91.

Brooks-Gunn, J., Duncan, G. J., \& Aber, J. L. (Eds.). (1997). Neighborhood poverty: Contexts and consequences for children (Vol. 1). New York: Russell Sage Foundation.

Brooks-Gunn, J., Duncan, G. J., Klebanov, P. K., \& Sealand, N. (1993). Do neighborhoods influence child and adolescent development? American Journal of Sociology, 99(2), 353-395.

Brown, B. V., \& Emig, C. (1999). Prevalence, patterns and outcomes. In D. J. Beshrov (Ed.), America's disconnected youth. Washington, DC: Child Welfare League of America.

Burdick-Will, J., Ludwig, J., Raudenbush, S. W., Sampson, R. J., Sanbonmatsu, L., \& Sharkey, P. (2011). Converging evidence for neighborhood effects on children's test scores: An experimental, Quasiexperimental, and observational comparison. In G. J. Duncan \& R. J. Murnane (Eds.), Opportunity? Rising inequality, schools and children's life chances. NY: Russell Sage Foundation.

Card, D., \& Rothstein, J. (2007). Racial segregation and the black-white test score gap. Journal of Public Economics, 91(11-12), 2158-2184.

Carter, P. L. (2005). Keepin' it real: School success beyond black and white. New York: Oxford University Press.

Case, A.C. \& Katz, L.F. (1991). The company you keep: The effects of family and neighborhood on disadvantaged youths, NBER Working Papers, Vol. 3705. 
Catsambis, S., \& Andrew, B. (2001). Does neighborhood matter? Family, neighborhood, and school influences on eighth-grade mathematics achievement. Sociological Focus, 43(4), 435-457.

Clark, R. L. (1992). Neighborhood effects on dropping out of school among teenage boys. Washington, DC: Urban Institute.

Cook, T. D. (2003). The case for studying multiple contexts simultaneously. Addiction, 98(1), 151-155.

Cook, T. D., Herman, M. R., Phillips, M., \& Settersten, R. A., Jr. (2002). Some ways in which neighborhoods, nuclear families, friendship groups, and schools jointly affect changes in early adolescent development. Child Development, 73(4), 1283-1309.

Cook, P., \& Ludwig, J. (1998). The burden of acting white: Do black adolescents disparage academic achievement. In C. Jencks \& P. Meredith (Eds.), The black-white test score gap. Washington, DC: The Brookings Institution.

Crane, J. (1991). The epidemic theory of ghettos and neighborhood effects on dropping out and teenage childbearing. American Journal of Sociology, 96, 1226-1259.

Cubbin, C., Santelli, J., Brindis, C. D. \& Braveman, P. (2005). Neighborhood context and sexual behaviors among adolescents: Findings from the National Longitudinal Study of Adolescent Health. Perspectives on Sexual and Reproductive Health, 37(3), 125-134.

Cutler, D. M., \& Glaeser E. L. (1997). Are ghettos good or bad? Quarterly Journal of Economics, 112(3), $827-872$.

Dobbie, W. \& Fryer, R. G. (2009). Are high quality high schools enough to close the achievement gap? Evidence from a social experiment in Harlem. National Bureau of Economic Research, No. 15473.

Downey, D., Ainsworth, J. W., \& Qian, Z. (2009). Rethinking the attitude achievement paradox among blacks. Sociology of Education, 82(1), 1-19.

Ellen, I. G., \& Turner, M. A. (1997). Does neighborhood matter? Assessing recent evidence. Housing Policy Debate, 8(4), 833-866.

Ensminger, M. E., Lamkin, R. P., \& Jacobson, N. (1996). School leaving: A longitudinal perspective including neighborhood effects. Child Development, 67(5), 2400-2416.

Evans, W. N., Oates W. E., \& Schwab, R. M. (1992). Measuring peer group effects: A study of teenage behavior. Journal of Political Economy, 100(5), 966-991.

Flores-Gonzalez, N. (2002). School kids/street kids: Identity development in latino students. New York, NY: Teachers College Press.

Fordham, S., \& Ogbu, J. (1986). Black students' school success: Coping with the "burden of 'acting White'. The Urban Review, 18, 176-206.

Frank, R., Cerda, M., \& Rendón, M. (2007). Barrios and burbs: Residential context and health-risk behaviors among angeleno adolescents. Journal of Health and Social Behavior, 48(3), 283-300.

Fry, R. (2003). Hispanic youth dropping out of US schools: Measuring the challenge. Washington, DC: Pew Hispanic Center.

Garner, C. L., \& Raudenbush, S. W. (1991). Neighborhood effects on educational attainment: a multilevel analysis. Sociology of Education, 62, 251-262.

Goldsmith, P. R. (2009). Schools or neighborhoods or both? Race and ethnic segregation and educational attainment. Social Forces, 87(4), 1913-1941.

Guryan, J. (2004). Desegregation and black dropout rates. American Economic Review, 94(4), 919-943.

Hair, E. C., Moore, K. A., Ling, T. J., \& McPhee-Baker, C. (2009). Youth who are "disconnected” and those who then reconnect: Assessing the influence of family, programs, peers and communities. Washington, DC: Child Trends Research Brief.

Haller, W., Portes, A., \& Lynch, S. M. (2011). Dreams fulfilled, dreams shattered: Determinants of downward assimilation in the second generation. Social Forces, 89(3), 733-762.

Hanushek, E. A., Kane, J. F., \& Rivkin, S. G. (2009). New Evidence about Brown v. Board of Education: The complex effects of school racial composition on achievement. Journal of Labor Economics, 27(3), 349-383.

Harding, D. J. (2003). Counterfactual models of neighborhood effects: The effect of neighborhood poverty on dropping out and teenage pregnancy. American Journal of Sociology, 109(3), 676-719.

Harding, D. J. (2010). Living the drama: Community, conflict, and culture among inner city boys. Chicago: University of Chicago Press.

Harding, D., Gennetian, L., Winship, C., Sanbonmatsu, L., \& Kling, J. (2011). Unpacking Neighborhood Influences on Education Outcomes: Setting the Stage for Future Research. In G. J. Duncan \& R. Murnane (Eds.), Wither opportunity? Rising inequality, schools and children's life chances. NY: Russell Sage Foundation. 
Harris, A. L. (2011). Kids don't want to fail: Oppositional culture and the black-white achievement gap. Cambridge, MA: Harvard University Press.

Hoxby, C. M. (2000). Peer effects in the classroom: learning from gender and race varation. National Bureau of Economic Research: Working Paper \#7867.

Jencks, C., \& Mayer, S. (1990). The social consequences of growing up in a poor neighborhood. In L. Lynn \& M. McGreary (Eds.), Inner-City Poverty in the United States. Washington, DC: National Academy Press.

Jencks, C., Smith, M., Acland, H., Bane, M. J., Cohen, D., Gintis, H., et al. (1972). Inequality: A reassessment of the effect of family and schooling in America. New York: Basic Books.

Johnson, O. (2010). Assessing neighborhood racial segregation and macroeconomic effects in the education of African Americans. Review of Educational Research, 80(4), 527-575.

Johnson, O. (2012). A systematic review of neighborhood and institutional relationships related to education. Education and Urban Society, 44(4), 471-511.

Kawachi, I., \& Berkman, L. F. (Eds.). (2003). Neighborhoods and health. Oxford: Oxford University Press.

Konstantopoulos, S., \& Borman, G. D. (2011). Family background and school effects on student achievement: A multilevel analysis of the Coleman data. Teachers College Record, 113(1), 97-132.

Krueger, P. M., Bond-Huie, S. A., Rogers, R. G., \& Hummer, R. A. (2004). Neighborhoods and homicidal mortality: An analysis of race/ethnic differences. Journal of Epidemiology and Community Health, 58(3), 223-230.

Landale, N. S., Oropesa, R. S., \& Llanes, D. (1998). Schooling, work and idleness among Mexican and non-Latino White adolescents. Social Science Research, 27, 457-480.

Lee, V. E. (2000). Using hierarchical linear modeling to study social contexts: The case of school effects. Educational Psychologist, 35, 125-141.

Lee, V. E., \& Burkam, D. T. (2003). Dropping out of high school: The role of school organization and structure. American Educational Research Journal, 40(2), 353-393.

Leventhal, T., \& Brooks-Gunn, J. (2000). The neighborhoods they live in: The effects of neighborhood residence on child and adolescent outcomes. Psychological Bulletin, 126(2), 309-337.

Massey, D. S., \& Denton, N. A. (1993). American apartheid: Segregation and the making of the underclass. Cambridge: Harvard University Press.

Mateu-Gelabert, P., \& Lune, H. (2003). School violence: The bidrectional conflict flow between neighborhood and school. City and Community, 2(4), 353-369.

Mateu-Gelabert, P., \& Lune, H. (2007). Street codes in high school: School as an educational deterrent. City and Community, 6(3), 173-191.

McNeal, R. B. (1997). High school dropouts: A closer examination of school effects. Social Science Quarterly, 78, 209-222.

Moore, J., \& Pinderhughes, R. (1993). In the barrios: Latinos and the underclass debate. NY: Russell Sage Foundation.

Mosteller, F., \& Moynihan, D. P. (Eds.). (1972). On equality of educational opportunity. New York: Random House.

Noguera, P. (2003). City schools and the American Dream: Reclaiming the promise of public education. New York, NY: Teachers College Press.

Ogbu, J. U. (1991). Immigrant and involuntary minorities in comparative perspectives. In J. Ogbu \& M. Gibson (Eds.), Minority status and schooling: A comparative study of immigrant and involuntary minorities. New York: Garland Publishing Co.

Orfield, G., \& Eaton, S. E. (1997). Dismantling desegregation: The quiet reversal of Brown vs. Board of Education. New York, NY: The New Press.

Orfield, G., \& Lee, C. (2005). Why segregation matters: Poverty and educational inequality. Cambridge: Civil Rights Project, Harvard University.

Oropesa, R. S., \& Landale, N. S. (2009). Why do immigrant youths who never enroll in U.S. schools matter? School enrollment among Mexicans and non-Hispanic Whites. Sociology of Education, 82, 240-266.

Osgood, D. W., Foster, E. M., Flanagan, C., \& Ruth, G. R. (Eds.). (2006). On your own without a net: The transition to adulthood for vulnerable populations. Chicago: University of Chicago Press.

Owen, A. (2010). Neighborhoods and schools as competing and reinforcing contexts for educational attainment. Sociology of Education, 83, 287.

Plotnick, R. D., \& Hoffman, S. (1999). The effects of neighborhood characteristics on young adult outcomes: Alternative estimates. Social Science Quarterly, 80(1), 1-18. 
Pong, S., \& Hao, L. (2007). Neighborhood and school factors in the school performance of immigrants' children. International Migration Review, 41(1), 206-241.

Portes, A., \& Hao, L. (2004). The schooling of children of immigrants: Contextual effects on the educational attainment of the second generation. Proceedings of the National Academy of Sciences of the United States of America, 101(33), 11920-11927.

Portes, A., \& MacLeod, D. (1996). Educational progress of children of immigrants: The roles of class, ethnicity, and school context. Sociology of Education, 69(4), 255-275.

Portes, A., \& Rumbaut, R. G. (2001). Ethnicities: Children of immigrants in America. Berkeley, CA: University of California Press.

Portes, A., \& Zhou, M. (1993). The new second generation: Segmented assimilation and its variants. Annals of the American Academy of Political and Social Science, 530, 74-96.

Powers, D. A. (1994). Transitions into idleness among White, Black and Hispanic youth: Some determinants and policy implications of weak labor force attachment. Sociological Perspectives, 37(2), 183-201.

Raudenbush, S. W., \& Bryk, A. S. (2002). Hierarchical linear models: Applications and data analysis methods (2nd ed.). NY: Sage Publications.

Raudenbush, S. W., \& Willms, J. D. (1995). The estimation of school effects. Journal of Educational and Behavioral Statistics, 20, 307-335.

Rivkin, S. G. (2001). Tiebout sorting, aggregation and the estimation of peer effects. Economics of Education Review, 20, 201-209.

Rumberger, R. W. (1995). Dropping out of middle school: A multilevel analysis of students and schools. American Educational Research Journal, 32, 583-625.

Rumberger, R. W. (2011). Dropping out: Why students drop out of high school and what can be done about it. Cambridge, MA: Harvard University Press.

Rumberger, R. W., \& Lim, S. A. (2008). Why students drop out of school: A review of 25 years of research. California Dropout Research Project Report \#15.

Rumberger, R. W., \& Palardy, G. J. (2005). Does segregation still matter? The impact of student composition on academic achievement in high school. Teachers College Record, 107(9), 1999-2045.

Rumberger, R. W., \& Thomas, S. L. (2000). The distribution of dropout and turnover rates among urban and suburban high schools. Sociology of Education, 73(1), 39-67.

Sampson, R., Morenoff, J. D., \& Gannon-Rowley, T. (2002). Assessing "neighborhood effects": Social processes and new directions in research. Annual Review of Sociology, 22, 443-478.

Sampson, R., Morenoff, J. D., \& Raudenbush, S. (2005). Social anatomy of race/ethnic disparities in violence. American Journal of Public Health, 95(2), 223-232.

Sampson, R. J., \& Sharkey, P. (2008). Neighborhood selection and the social reproduction of concentrated racial inequality. Demography, 45(1), 1-29.

Sanbonmatsu, L., Kling, J. R., Duncan, G. J. \& Brooks-Gunn, J. (2006). Neighborhoods and academic achievement: Results from the moving to opportunity experiment. The Journal of Human Resources, 41(4), 649-691.

Sander, W. (2001). Chicago public schools and student achievement. Urban Education, 36(1), 27-38.

Settersten, R., Furstenberg, F., \& Rumbaut, R. (Eds.). (2005). On the frontier of adulthood: Theory, research and public policy. Chicago: University of Chicago Press.

Sharkey, P. (2010). The acute effect of local homicides on children's cognitive performance. Proceedings of the National Academy of Sciences, 107, 11733-11738.

Sharkey, P. (2012). An alternative approach to addressing selection into and out of social settings: Neighborhood change and African American children's economic outcomes. Sociological Methods \& Research, 41(2), 251-293.

Sharkey, P., \& Elwert, F. (2011). The legacy of disadvantage: Multigenerational neighborhood effects on cognitive ability. American Journal of Sociology, 116, 1934-1981.

Solorzano, D. (1992). Chicano mobility aspirations: A theoretical and empirical note. Latino Studies Journal, 3, 48-66.

Sykes, B., \& Musterd, S. (2011). Examining neighborhood and school effects simultaneously what does the Dutch evidence show? Urban Studies, 48(7), 1307-1331.

Teitler, J. O., \& Weiss, C. C. (2000). Effects of neighborhood and school environments on transition to first sexual intercourse. Sociology of Education, 73(2), 112-132. 
Tyson, K., Darity, W. J., \& Castellino, D. R. (2005). It's not “a Black thing:” Understanding the burden of acting White and other dilemmas of high achievement. American Sociological Review, 70(4), 582-605.

Upchurch, D. M., Aneshensel, C. S., Sucoff, C. A., \& Levy-Storms, L. (1999). Neighborhood and family contexts of adolescent sexual activity. Journal of Marriage and Family, 61(4), 920-933.

Warikoo, N. (2011). Balancing acts: Youth culture in the global city. Berkeley, CA: University of California Press.

Wilson, W. J. (1987). The truly disadvantaged: The inner city, the underclass and public policy. Chicago: University of Chicago Press.

Wilson, W. J. (1996). When work disappears: The world of the new urban poor. New York: Random House. 